Max-Planck-Institut für demografische Forschung

Max Planck Institute for Demographic Research

Konrad-Zuse-Strasse 1 - D-18057 Rostock = Germany = Tel +49 (0) 3812081 - 0 - Fax +49 (0) 3812081 - 202 - www.demogr.mpg.de

MPIDR Working Paper WP 2019-014 I July 2019

\title{
Retraditionalization as a Pathway to Escape Lowest-Low Fertility? \\ Characteristics and Prospects of the Eastern European "Baby Boom"
}

\author{
Sebastian Klüsener \\ Aiva Jasilioniene I jasilioniene@demogr.mpg.de \\ Viktoriya Yuodeshko
}

This working paper has been approved for release by: Dmitri A. Jdanov (jdanov@demogr.mpg.de),
Head of the Laboratory of Demographic Data.
(C) Copyright is held by the authors.

Working papers of the Max Planck Institute for Demographic Research receive only limited review. Views or opinions expressed in working papers are attributable to the authors and do not necessarily reflect those of the Institute. 


\title{
Retraditionalization as a Pathway to Escape Lowest-Low Fertility? Characteristics and Prospects of the Eastern European "Baby Boom"
}

\author{
Sebastian Klüsener ${ }^{1,2,3}$, Aiva Jasilioniene ${ }^{2,3}$, Viktoriya Yuodeshko ${ }^{4}$ \\ ${ }^{1}$ Federal Institute for Population Research (Germany), \\ ${ }^{2}$ Max Planck Institute for Demographic Research (Germany), \\ ${ }^{3}$ Vytautas Magnus University (Lithuania), \\ ${ }^{4}$ Research Institute of Labour (Belarus)
}

Over the last two decades, Belarus and Russia have witnessed substantial fertility increases that have catapulted their total fertility rates from lowest-low fertility to levels above 1.7 children per woman. While it is frequently argued that greater gender equality is an important mechanism for overcoming low fertility, these developments seem to have instead been accompanied by a retraditionalization of gender attitudes. This paper uses the 2017 Belarusian Generations and Gender Survey to investigate the characteristics and prospects of the Eastern European "baby boom." We show that the fertility increases are driven by two main components: the recuperation of births postponed during the preceding post-communist transition crisis, and fertility increases among cohorts born in the 1980s. These cohorts also display very traditional gender attitudes. While the recuperation will not have a long-term impact, it is more uncertain whether or not the cohort fertility increases will be sustained.

\section{Acknowledgements}

This paper benefited from discussions with Brienna Perelli-Harris. In addition, we would like to thank Tom Emery for assistance with data questions, Olga Grigoriev for useful conversations and help with information searches, and Miriam Hils for language editing.

The study has been conducted in the framework of the project "Contemporary demographic problems in Belarus and Lithuania: variations, similarities, and ways for transition to sustainable development" (TAP LB-17-027) funded by the Research Council of Lithuania on the basis of the bilateral agreement on the partnership in the areas of science and technology between Lithuania and Belarus. 


\section{Searching for Pathways to Overcome Low Fertility}

Below-replacement fertility is a pressing issue for many developed countries. According to the 2015 Revision of the World Population Policies Database, 29 of the 44 covered European countries articulated the goal of increasing fertility levels (UN 2016). Discussions about the factors that cause fertility to fall below replacement levels, and about whether developed societies are able to positively influence fertility levels, have been central to the field of demography over the last 100 years (Kirk 1996; Van Bavel 2009; Lesthaeghe 2010). In recent years, there has been an increasing consensus, at least in the Western debate, that enhancements in gender equality bolstered by family policies supporting the reconciliation of family and career goals is the most promising path for high-income countries to escape low fertility (Esping-Andersen and Billari 2015; Goldscheider et al. 2015). However, the recent stark (period) fertility decreases in countries with high levels of gender equality, such as Norway and Iceland, raise at least some doubt about the universality of these propositions. Moreover, even in highly developed societies, there are still substantial shares of the population who favor traditional family forms in which women and men specialize in different tasks (e.g., Hudde 2018). In this division of roles, women usually tend to focus on the private sphere of the household and on raising children, while men tend to concentrate on gainful economic activities in the public sphere. Attitudes that support such male breadwinner arrangements remain widespread in Eastern Europe in particular (Lappegård, Klüsener, and Vignoli 2018), and have in part even increased in relevance as the legacy of the promotion of gender equality by communist-era governments has faded (Fodor and Balogh 2010). It should also be noted that the days when male breadwinner models were very dominant in Western societies are not that far in the past. Indeed, such arrangements were very prevalent in the "Golden Age of Marriage" of the 1950s and the 1960s, when many societies experienced a baby boom.

During the 1990s, it appeared that economic and social conditions in Europe were generally converging. Many societies in Central and Eastern Europe moved away from having centrally planned economies and toward the adoption of market-oriented systems that already existed in Western Europe (Kuzio 2001; Aslund 2013). This transition was often fostered by insufficiencies in the centrally planned economies, which led to many countries experiencing deep structural economic crises in the transition period of the 1990s (Alam et al. 2005; Sobotka 2003). The convergence in economic systems was paralleled by a convergence in family formation patterns. Non-marital fertility started to increase in Central and Eastern Europe after 1990, in part due to the economic crises, but also due to the spread of more liberal values (Thornton and Philipov 2009). These developments appeared to suggest that if Eastern Europe continued to follow this path, the strategies that had enabled some Western European societies to bring their fertility close to replacement levels might also serve as a blueprint for Eastern Europe. 
However, since the dawn of the new millennium, a number of Eastern European countries have left the path of convergence. This is particularly true for Belarus and Russia, which have undergone a period of societal restoration. During this restoration, the total fertility rates in these countries have increased substantially, from levels of around 1.1-1.3 in 2000 to more than 1.7 in 2016 (see also Fig. 1). At the same time, a number of Eastern European societies have experienced a decrease in the share of non-marital births; a development that runs counter to the trends in other parts of Europe, where the non-marital birth ratio is either still growing or stagnating at high levels (Klüsener 2015). The decreases were especially strong in Belarus (2005: 24\%, 2016: 13\%) and Russia (2005: 30\%, 2016: 21\%) (Eurostat; Klüsener 2015; Rosstat). The question of to what degree new family policies in Belarus and Russia that tend to bolster the traditional male breadwinner model have contributed to these trends is disputed. Freijka and Zacharov (2013) have argued that the return to higher fertility is not driven by family policies, but by the recuperation of births at higher ages that were postponed during the crisis years. Similar recuperation arguments have been put forward by others for Central and Eastern European countries (e.g., Bongaarts and Sobotka 2012; Fox, Klüsener, and Myrskylä 2018). Moreover, the decrease in the share of births outside of marriage is likely to be affected by this trend to some degree, as (higher order) births among older mothers are more likely to occur within marriage (Perelli-Harris and Gerber 2011).

[Figure 1 about here]

The multiple equilibria argument put forward by Esping-Andersen and Billari (2015), which we will discuss in more detail below, allows to develop a theoretical expectation that depending on the level of gender equality achieved, fertility increases could be realized not only through gender equality enhancements but also through gender equality reductions. Thus, the $21^{\text {st }}$ century "baby boom" in Eastern Europe might provide us with an example in which the return to relatively high low fertility levels is achieved by a retraditionalization of societies, coupled with a period of economic stabilization after a drastic economic crisis. If this were the case, the questions of to what degree such a pathway might also be viable for other countries, and of whether such "baby booms" have the potential to last, would arise. It should be noted that the mid- $20^{\text {th }}$-century baby boom in industrialized countries, which was also characterized by some tendencies toward retraditionalization (Van Bavel and Reher 2013), came to an abrupt end when the cohorts who had not directly experienced the atrocities and destructions of World War II reached childbearing age. Will this also be the destiny of the Eastern European "baby boom" once the post-transition cohorts reach prime childbearing ages? One important counterargument to this proposition might be that Eastern Europe has a longstanding legacy of gender inequality. Historical research based on household structure data shows that today's East-West disparities in gender inequalities across Europe were also visible in the $19^{\text {th }}$ century (Szołtysek et al. 2017). The long legacy of higher levels of gender inequality in Eastern Europe might imply that Eastern Europe has potentially more pathways to 
escape low fertility than Western European societies, which are currently strongly leaning toward higher levels of gender equality.

The 2017 Belarusian Generations and Gender Survey data provide us with an excellent opportunity to take a detailed look at the characteristics and prospects of the recent fertility trends in Belarus. As Belarus and Russia share many similarities in terms of their socioeconomic and political development, our findings may also be relevant for understanding the determinants and prospects of the recent fertility developments in Russia. These similarities include that after undergoing an initial liberalization process in the 1990s, which was accompanied by economic turmoil that brought hardship to large parts of the population, the societies both in Belarus and Russia elected leaders who tended to prioritize the stabilization of the economic and political situation. As a result, the governments of both countries regained substantial control over the economic and political processes in their respective societies. In terms of fertility trends, the similarities between Belarus and Russia are apparent not only in the fertility increases in recent decades but also in the most recent numbers for 2017. These indicate that both countries experienced a fertility decrease for the first time in this decade. This trend change raises the question of whether we are already seeing the end of the "baby boom," or whether this was just a temporary dip.

With this paper, we follow two main research objectives. The first is to explore to what degree the fertility increases observed in Belarus in recent decades are driven by a recuperation of births that were postponed during the post-communist transition crisis of the 1990s and 2000s. If the fertility increases were mainly caused by recuperation, they are likely to be of a temporary nature only. Our results show that recuperation is indeed playing a role. At the same time, we also detect cohort fertility increases among cohorts born in the 1980s, with surges in transitions to third births among these younger cohorts being particularly remarkable. The second objective is to gain a better understanding of the characteristics of the cohorts who are at the center of the current "baby boom." Our findings provide indications that respondents born in the 1980s and early 1990s show more conservative gender attitudes than older cohorts. As the "baby boom" is especially concentrated in rather conservative rural areas (Belstat 2017), these more conservative attitudes might contribute to the boom. Overall, our findings suggest that at least a portion of the "baby boom" is not just driven by recuperation. However, it is uncertain whether the cohort fertility increases might be sustained, also considering that cohorts born after 1995 display at least so far less traditional gender attitudes than those born in the 1980s and early 1990s. 


\section{Universal vs. Country-specific Pathways to Escape Low Fertility}

Whether and to what degree specific demographic developments are universal is a recurring theme in global debates on population and development (Caldwell 2001; IPC 2009; Thornton 2013; Drummond et al. 2014; Lima et al. 2018). Some processes, such as the demographic transition, fertility postponement, and the longevity revolution, seem to affect virtually all populations around the globe. By contrast, other developments, such as changes in family formation patterns or in the prevalence of same-sex unions, continue to vary substantially across countries. For a long time, it looked as if conservative populations were able to achieve higher fertility outcomes. In Europe, for example, the fertility declines that took place during the demographic transition were often delayed in rural and/or more religious areas (e.g., Goldstein and Klüsener 2014), and in a number of rather conservative societies, such as Italy, Portugal, and Spain. However, this pattern changed in the late $20^{\text {th }}$ century, when the relationship between female labor force participation and fertility shifted from negative to positive across high-income countries over a short space of time (Brewster and Rindfuss 2000; Engelhardt and Prskawetz 2004). As we mentioned above, in recent years, the debate about fertility in high-income countries has been dominated by the perspective that increases in fertility are best achieved through enhancements in gender equality (Esping-Andersen and Billari 2015; Goldscheider, Bernhardt, and Lappegård 2015). These theories describe a Ushaped pattern of development in which fertility initially decreases due to higher female labor participation and elevated normative confusion about appropriate gender roles, and then increases again if institutional adjustments are also made to support dual-earner couples in reconciling family and work. It is, however, unclear whether all societies will follow such a Ushaped path in a unidirectional way, or whether some societies will experience periods during which more traditional gender roles are resurfacing. If the U-shaped path is indeed reflective of reality, and if certain countries are at the turning point of the U-shaped path, then retraditionalization might actually lead to fertility increases. We will investigate whether Belarus provides us with such a case by examining to what degree cohort variation in fertility behavior relates to cohort variation in gender attitudes.

However, in addition to trends in gender attitudes, the development of family policies might play a role in the recent fertility increases (Frejka et al. 2016). Neyer and Andersson (2009) have stressed that identifying critical junctures characterized by drastic social policy changes with relevance for family behavior can help us understand the impact of policies on fertility and family behavior. But in the case of Belarus, it is difficult to single out such critical junctures, as there have been frequent reforms in the country's social policies, especially since the early 2000s. In the following, we will provide a short overview of the development of family policies in Belarus since the 1980s, when the country was still part of the Soviet Union. In the 1980s, the Soviet Union extended its family support schemes (Imbrogno 1986). In addition to policies to provide free housing and expanding public child care facilities, the support for 
families included the introduction of a lump-sum benefit for every newborn child, a parental leave benefit paid during the child's first year of life, as well as the option to take unpaid child care leave until the child reached the age of 1.5 years. During the crisis period of the 1990s, the Belarusian government extended the paid child care leave until the child reached the age of three. However, the levels of these leave payments were very low, shifting between $6 \%$ and $17 \%$ of the average wage in the 1990 s and early 2000 s. At the same time, access to public child care decreased as many kindergartens and nurseries that had been operated by former state-owned enterprises were closed down.

Throughout the 2000s, various family support schemes were further expanded, especially in the area of housing policies (Shakhotko 2009; Shakhotko and Shakhotko 2018; Yuodeshko 2012, 2017). In 2000, the Belarusian government introduced concessional loans granted for the construction, reconstruction, or acquisition of housing. The free housing support schemes were suspended after the collapse of the Soviet Union. Thus, during the 1990s, access to housing became a serious problem, and was especially acute among young families (Eremenko 2016). Important policy reforms aimed at improving access to housing were implemented in 2004. These reforms were primarily targeted at families with three or more children and at families residing in rural areas. The adopted measures included reduced interest rates on concessional housing loans, extended loan repayment periods, financial assistance to families who failed to meet the repayment terms, and other measures. Multiple amendments to the housing policies were implemented during the years that followed (especially in 2007), from which families with fewer than three children also benefited. These measures contributed substantially to the further improvement of the housing conditions of families. Moreover, child care allowances were increased and access to public child care was improved. At the end of 2011, the birth grant awarded to parents was doubled, to about $\$ 1,100$ for a first birth and to about $\$ 1,600$ for a second or higher order birth. In 2013, access to child care was significantly increased, and the cost of care was linked to the average wage in the country. For a child up to age three, parents received subsidies equivalent to $35 \%$ of the average wage for the first child, $40 \%$ for subsequent children, and $45 \%$ for a disabled child. Furthermore, in 2015, a "family capital" support scheme was introduced that was similar to the Russian "maternal capital" (Zakharov 2008). In Belarus, the "family capital" (\$10,000) is granted to parents at the birth of a third or subsequent child, but can only be used (for a limited rage of purposes) after the child turns 18 years old. As all of these reforms were implemented since 2000 during a period of general economic recovery, it would be difficult to disentangle the policy effects from the recovery effects. Nonetheless, understanding of how family policies have developed in Belarus in recent decades will be relevant for interpreting our findings.

One challenge we face in exploring the question of whether a societal restoration process is likely to last is that backlashes might occur swiftly. The data we have available provide us with information on attitudes, but existing research shows that responses to attitude questions 
might be affected by social desirability bias (Nederhof 1985; Fisher 1993). Another potential problem is that people's attitudes might be adjusted to their behavior, such as having a first child or transitioning to a higher-parity child (see Brandstädter and Rothermund 2002; Huinink and Kohli 2014). This could affect our analysis of attitudinal trends over cohorts. Generally, we believe that looking at actual behavior, such as having children early or transitioning to a third birth, is more informative when seeking to understand family orientation than focusing on attitudes. Nevertheless, when the goal is to learn more about potential future fertility trend trajectories, examining attitudes can be helpful (Beets, Liefbroer, and Gierveld 1999). However, caution should be applied when studying the attitudes and cohorts of young adult ages in particular, as attitudes reported in this life phase can still change quite significantly (Beets et al. 1999), especially after entry into parenthood (Baxter et al. 2014).

\section{Data and Analytical Strategy}

We use data from the 2017 Generations and Gender Survey (GGS) in Belarus, which provides us with detailed information on union and fertility histories and gender attitudes for 9,994 individuals (5,514 females and 4,480 males) aged 18-89 years. We analyze the official dataset (Version 1.0), to which we were granted access to through the Generations and Gender Programme's (GGP) web portal (https://www.ggp-i.org/). The web portal offers detailed background information about both the GGP and the data collection. Throughout the analysis, we mainly focus on women, although we also look at the gender attitudes of men. For all analyses, we apply post-stratification weights. A particular emphasis we place on urban-rural differences in the observed patterns. Since the dataset that we are able to access through the GGP web portal does not specify whether a respondent's place of residence is in an urban or a rural area, we added this information from a national GGS dataset. In Belarus, the distinction between urban and rural settlements is mostly based on population size, with 2,000 inhabitants serving as the cut-off point. To investigate the representativeness of the GGS data, we first compared trends in the mean age at childbirth by birth order recorded in the survey with information obtained from the Human Fertility Database (HFD 2018). The outcomes are presented in the appendix of this paper. Overall, the results of the comparison provide support for the view that the GGS data capture trends for first and second births relatively well. The fit for third births seems to be fine for the 1990s and early 2000s, while we witness bigger deviations especially in the 1980s and the most recent years. Our overall conclusion from this comparison is that the GGS data seem to be reliable enough to enable us to perform our analyses. However, the outcomes for third births should be interpreted with some caution.

In our investigation, we use life table methods and hazard models to obtain an understanding of the demographic components of the recent fertility trends. We first look at singledecrement life tables showing transitions to first, second, and third births. Life tables are gen- 
erated for both synthetic and real cohorts of women following the life table construction approach developed by Andersson and Philipov (2002) for an analysis of similarly structured Fertility and Family Survey data. This approach was applied to GGS data by Philipov and Jasilioniene (2008). In the cohort life table analysis, we examine the fertility patterns of six cohorts of women born in 1950-1959, 1960-1969, 1970-1974, 1975-1979, 1980-1984, and 1985+. The synthetic-cohort life tables are constructed for five period intervals: 1984-1990, 1991-1997, 1998-2004, 2005-2011, and 2012-2017. The dates of events are measured in years and months. For the exact timing of events, we use the middle of the reported month. The life table values are interpreted as the cumulative percentage of individuals who have experienced the studied event by a specific age. To examine the recuperation aspect more closely, we run hazard models (smoothed hazard rates plotted by "sts graph, hazard" in Stata) that enable us to explore how age schedules and durations between births have changed over time. To study cohort patterns in gender attitudes, we analyze responses to gender attitude questions posed in the GGS.

\section{Characteristics of the "Baby Boom" in Belarus}

In investigating cumulative fertility from both a period and cohort perspective, we will first look at the patterns for the whole of Belarus. When presenting the cumulative percentages, we have decided that for the higher order births we will not condition on whether a woman had actually already transitioned to the preceding parity. This allows us to directly identify in the cohort graphs the share of women who have at least two or three children. The alternative of using conditional cumulative percentages would make such assessments more difficult, since, for example, the share of women who transitioned from the second to the third child would be provided as the share of women who had at least two children.

As a first step, we will look at the period synthetic cohort outcomes (Fig. 2). The data for first births show the well-documented phenomenon that the transition to first birth is almost universal in Belarus. In all of the periods considered, around $90 \%$ of all women of these synthetic cohorts would have given birth to a first child by the end of their reproductive life span. A trend toward postponement is visible, as in the later three periods, the cumulative percentages increase at higher ages than in the first two periods (1984-1990, 1991-1997). This trend is confirmed by the HFD data depicting the mean age at first birth, which started to increase in the second half of the 1990s (Fig. A1). Bigger disparities over time are visible for second births. Here we see that in the post-Soviet crisis period, transitions to second births occurred much less frequently. The ultimate (synthetic cohort) level of having a second child decreased from above $70 \%$ in the late 1980 s to $50 \%-60 \%$ in the 1990 s and 2000 s. In addition, we see a substantial postponement in the ages of women at which the transition to second birth occurs. In the last period (2012-2017), however, the cumulative percentage increased 
again to around $70 \%$, and was thus close to the level registered in the 1980s. For third births, for which the data are a bit less reliable, we observe generally a similar pattern over time. Whereas in the 1980s relatively few third births were to women older than age 32 , this is no longer the case. Thus, the recent increase in births to older mothers has contributed to rising third birth levels.

[Figure 2 about here]

In order to gain a better understanding of potential recuperation trends, we turn to the cohort perspective (Fig. 3). For the progression to first birth, we see even fewer differences between the cohorts than between periods in the ultimate share of women entering motherhood. With the exception of the cohorts born 1985 or later, who were aged 32 or younger when the survey was conducted, around $90 \%$ of all women had at least a first child at the latest observable age. The trajectory of the cohorts born 1985 or later seems to closely follow the one of the cohorts born 1980-1984. Among the younger cohorts, we also see indications of postponement and recuperation trends. For example, we observe that compared to earlier cohorts, fewer of the women born in 1975-1979 transitioned to a first birth in their twenties, but that these women caught up to previous cohorts after age 30 (i.e., after 2005). The tendency to postpone the first birth was even stronger among the cohorts born in 1980-1984 and 1985 or later.

[Figure 3 about here]

For the transition to second birth, we see a rather large degree of postponement starting with the cohorts born in 1970-1974. Women of this cohort were most affected by the postcommunist transition crisis, as it gained momentum precisely at the time when they were reaching childbearing ages. For this reason, we can expect that these women were the most likely to end up with the lowest cumulative percentage among all the cohorts considered. The cohorts born in 1975-1979 and in 1980-1984 had their second births much later in life than the older cohorts, but recuperated their postponed fertility at higher reproductive ages. This recuperation trend is particularly pronounced among the cohorts born in 1980-1984. The share of women in these cohorts who had a second birth will most likely be higher than that of the cohorts born in 1960-1969. This finding supports the view that the recent increases are not just driven by a recuperation pattern, but by a rebound in cohort fertility levels. In the youngest cohorts (1985+), the cumulative percentage of those who already had a second child, as assessed in 2017, was among the oldest women already close to 50\%, which suggests that the degree of postponement is less pronounced in the youngest cohorts than in the preceding ones.

Compared to first and second births, third births are much less common in Belarus. However, the cohort patterns for third births are still remarkable. Even though the cohorts born in 19801984 (aged 32-37 in 2017) had not yet reached the end of their reproductive life spans when 
the survey was conducted in 2017, the share of women in this cohort who had at age 37 at least three children (17\%) was already the highest among the considered cohorts. Indeed, this percentage is even higher than the levels reached by the women born in 1950-1959, most of whom completed their reproduction during the Soviet era. Currently, this upward trend does not seem to be slowing down, as even among the cohorts born in 1985, a full 14\% had a third child by 2017. The patterns for the younger cohorts again suggest that we are seeing not just the recuperation of postponed births, but quantum increases in fertility.

There are substantial differences in the fertility patterns of women living in urban and in rural areas, especially when it comes to second and third births. In interpreting the graphs by place of residence presented below, it is important to keep in mind that the survey data do not include the migration histories of the respondents. This implies that we derived the plots conditional on the place of residence when the survey was conducted. Thus, for example, we cannot know for sure whether a birth to a women residing in an urban area actually occurred in an urban area. However, since internal migration intensities after age 30 are rather low (Bell and Muhidin 2009), we believe that despite this limitation, our analyses can provide an impression of the urban-rural differences in fertility outcomes.

For first births, the variation between urban and rural residents was marginal in terms of both quantum and tempo (see Fig. 4 and 5). This finding again underlines the universality of motherhood in Belarus. For second births, we see in the period graphs (Fig. 4) that in the 1980s, women living (at the time of the survey) in urban areas had lower transition rates to second births than those living in rural areas. The decreases in second births after 1991 were also larger among urban women. Moreover, levels of second births remained higher among rural residents in the very last study period (2012-2017). During the Soviet era, third births were much more prevalent among rural than among urban women. Thus, the absolute reductions in third births during the post-Soviet period were also much larger among rural than among urban residents. However, in the last study period, levels of third births among urban women were by far the highest of all the periods considered. Among rural residents, the third birth numbers were slightly above the levels obtained for the 1980s.

[Figure 4 about here]

When we move to the cohort perspective, we again observe no significant differences in the progression to first birth between the cohorts living in urban and rural areas. For second births, the levels were lower for urban women, and especially for the cohorts most affected by the crises (1970-1974). Among the women of these cohorts, 51\% living in urban areas and $67 \%$ living in rural areas had a second child. The trend patterns are, however, very similar between rural and urban residents, and the return to the pre-transition levels seems to be more advanced among urban than among rural women. The pronounced postponement and recu- 
peration trends among the cohorts born in 1980-1984, which we pointed out at the country level, are particularly visible among the rural cohorts. Similarly, for the 1985+ cohorts, we witness that the tendency to have a second birth at a younger age is more pronounced among rural residents.

Turning to third births, we see that the cohorts born in 1980-1984 have very similar trajectories among both urban and rural residents. At the end of the observation period, around $15 \%$ $18 \%$ of both urban and rural women aged 35 and above already had a third birth. This is remarkable considering that in all of the other cohorts studied, the levels have been much higher among rural than among urban women. This is particularly the case for the last cohort group (1985+). In this latter cohort group, the trajectory to a third birth has been among urban women even faster than it was in the cohorts born in 1980-1984. Nonetheless, in recent years, the increases in third births among urban women have still been much smaller in scale than the massive increases detected for rural residents. Among all of the cohorts considered, the transition to third birth has been quickest in the rural cohorts born in 1985 or later: of these women, $30 \%$ had experienced a third birth by the time they reached their early thirties. Thus, these cohorts have already achieved the third birth levels of the cohorts who had spent most of their reproductive years in the Soviet era. The remarkable similarities in the trajectories of urban and rural women born in 1980-1984 might have occurred in part because during the post-Soviet transition crisis, economic growth returned to urban areas first (see also Alam et al. 2005 and Macours and Swinnen 2008). The pattern for the youngest cohorts suggests that in the rural areas in particular, women are increasingly having a third birth at a relatively young age. This trend might be related to policies that support big families with three or more children.

\section{[Figure 5 about here]}

To look at the postponement-recuperation trends in more detail, we turn to the smoothed hazard rates for second and third births. In Figure 5 we show the rates for second births, and in Figure 6 the rates for third births. For second births, the hazard peaks at around 3-4 years after the first birth in all of the periods. The highest hazards were recorded in the 1984-1990 period. But at that time, the hazard rates were quickly decreasing to very low levels 6-10 years after the first birth. During the crisis period (1991-1997, 1998-2004), the second birth hazards were at their lowest point, and there were no indications of recuperation. The situation was very different in the last two periods (2005-2011, 2012-2017). In the 2005-2011 period, we see a nearly bimodal shape, as almost a second maximum is visible at around 10 years after the first birth. Moreover, in the last period, the hazard rates of the transition to the second birth continued to be high even 10 years after the first birth. The hazard schedules for the second birth by age of the mother provide additional support for the view that recuperation is an important element of the recent fertility trends. We see a marked increase in the 
second birth hazard rates at older childbearing ages, especially in the last period (2012-2017). Urban and rural residents differed in terms of levels, but the overall trend patterns were very similar over time. Unlike for second births, for third births (Fig. 6) the hazards were by far the highest in the last period. This pattern was particularly pronounced among rural residents, where the women who made this transition tended not to wait very long, with the hazards swiftly decreasing 5-8 years after the second birth.

[Figure 6 about here]

The fertility patterns for the youngest cohorts suggest that they will indeed have cohort fertility outcomes that are higher than those of the cohorts who were of prime childbearing age during the 1990s and early 2000s. However, this trend is not necessarily linked to a retraditionalization of Belarusian society, as it might simply signal a return to higher fertility after the post-communist transition crisis, perhaps bolstered by the described extension of family policies. To look into this, we study the cohort patterns in responses to gender attitude questions in Tables 1 and 2. The first question of interest is whether it is the role of the woman or of the man to earn money for the family (Table 1). In all cohort groups apart from rural women born in the 1970s, the majority of respondents said they believe the man has the greater responsibility. These perceptions appear to have caused men to experience more pressure during the post-Soviet transition crises (see Cockerham 2012). However, we see shifts in these attitudes across cohorts. Interestingly, among women, the highest values were recorded not in the oldest cohorts, but in the cohorts at the center of the recent cohort fertility increases (1980-1994). In these cohorts, up to $60 \%$ of women indicated they subscribe to this view, whereas the values were 5-10 percentage points lower among women in other cohorts, including in the youngest cohort. Among men, those in the oldest cohorts and in the cohorts born in 1985-1989 were most likely to say they support the male breadwinner norm. In the younger cohorts, however, the peak values were less pronounced among men than among women. Overall, the gender differences related to these attitudes were lowest in the cohorts born after 1980. While we see quite large urban-rural differences in fertility outcomes, the differences in attitudes appear to be rather small, including for the youngest cohorts. Additional analyses in which we looked at differences by educational attainment did not return any big differences.

\section{[Table 1 about here]}

In Table 2, we look at attitudes regarding the responsibilities of women and men to take care of the home and the children. In all of the cohorts considered, the majority of respondents said they believe that women and men are equally responsible for bringing up children. But there were also substantial shares of respondents who expressed the view that this is primarily the role of women. Among both women and men, we find the least support for assigning this 
task to women among the cohorts born in the 1960s and the early 1970s, whereas support was relatively high among both the oldest and the youngest cohorts. Among women, this pattern is shown to be particularly pronounced for the cohorts born after 1990. Compared to women in the older cohorts, these women were more likely to assign the responsibility for bringing up children to women than to men. It thus appears that gender conflict about these issues is less likely to arise among these cohorts. If, however, women see themselves as having the greater responsibility to take care of the children, they might experience a double burden if they also have to contribute to the household income through employment. Again, additional analyses did not show big differences across educational attainment groups.

[Table 2 about here]

It is a bit difficult to interpret our findings on gender attitudes as the cohorts born in the 1980s were more likely to have small children at interview compared to older cohorts. Thus, they might be more confronted with work-family time conflict and might in this phase of the life course return to more traditional patterns of work division (Müller and Zillien 2016). Unfortunately, we do not have cohort trend data on gender attitudes for Belarus which would allow us to look at this in detail. However, for Russia trend data can be obtained from the European Social Survey (ESS). The gender attitudes question asked in 2008, 2010, and 2016 is phrased differently than in the GGS ("When jobs are scarce, men should have more right to a job than women"), and additionally we face issues with small sample sizes. Nevertheless, we find in Russia for 2016 a similar cohort pattern as in Belarus, with the cohorts born in the late 1980s and early 1990s reporting particular traditional gender attitudes. However, the trend data suggest that these attitudes gained ground when these cohorts reached ages in which many women transition to motherhood. Thus, we cannot rule out that the more traditional gender attitudes among the cohorts in the center of the "baby boom" might actually be driven by their current life course circumstances and their higher fertility levels. Overall, our analysis exemplifies that it is very difficult to assess the origins of cohort variation in gender attitudes if there is only data for one cross-section available.

\section{Prospects of the Eastern European "Baby Boom"}

When we consider the question of whether the current Eastern European "baby boom" fits into a universal pattern or is the result of unique local conditions, we conclude that it may be too early to make a call. So far, this "baby boom" seems to be similar to the mid- $20^{\text {th }}$-century baby boom in a number of ways (see Van Bavel and Reher 2013). In both periods, recuperation contributed substantially to the return to rising fertility rates. However, at later stages of these two periods, fertility increases in the succeeding cohorts also played an important role. In the mid- $20^{\text {th }}$-century baby boom, the increases were concentrated in the cohorts born dur- 
ing the Great Depression and its aftermath; these cohorts were still children during World War II. In the case of Eastern Europe, the recent "baby boom" seems to have been driven by the cohorts who were children when the Soviet Union collapsed. More research is needed to explore whether perhaps also the recuperation among older cohorts after the crisis-induced postponement had an effect on the cohort fertility increases among succeeding cohorts. In recent years, evidence has mounted that fertility events in an individual's social surroundings can influence own fertility decisions (Lois and Becker 2014; Mishra and Parasnis 2017). In a context in which many older women are recuperating postponed fertility, this will likely positively affect the frequency with which younger women experience births among their family members, coworkers, or other social contacts. This exposure to a greater frequency of fertility events might have a positive effect on the degree to which the fertility plans of these women are formed and realized. At the same time, as a result of discussions with older women who postponed their childbearing plans during the crisis, the succeeding younger cohorts might feel privileged to be less constrained in their childbearing plans, which might also lead to higher fertility outcomes. If these mechanisms play a role in recent fertility trends, then the parts of the quantum increases among younger cohorts that stem from positive "contagion effects" related to recuperation among older cohorts are likely not to last for long.

If fertility recuperation among older cohorts does turn out to positively affect fertility in succeeding cohorts due to an increased frequency of birth events, this pattern might also be relevant for a number of Western societies that are currently witnessing the end of a period of massive postponement (Goldstein, Sobotka, and Jasilioniene 2009). The slight cohort fertility increases among the cohorts born in the late 1970s (Myrskylä, Goldstein, and Cheng 2013) who succeeded the cohorts at the center of the postponement might be at least partly explained by such a mechanism. It would be a fruitful avenue for future research to explore this possibility theoretically with agent-based models, or empirically with datasets that contain information on social contacts of individuals and their fertility attitudes and behavior.

We pointed out that Eastern Europe has a legacy of higher levels of gender inequality than Western Europe (Szołtysek et al. 2017). This legacy might contribute to making the Eastern European "baby boom" last longer than the mid- $20^{\text {th }}$-century baby boom in the industrialized world. Whether this will happen we will learn in the years to come. One limitation of the current study is, however, that we were able to measure gender attitudes at one point in time only. Thus, it is difficult to say to what degree the less traditional attitudes among the youngest cohorts will prevail if these cohorts reach ages in which many women transition into motherhood, as child births can trigger the return to more traditional gender divisions of labor among couples (see also Baxter et al. 2014 and Höfner, Schadler, and Richter 2011). 
However, while Belarus' total fertility rate of 1.6 is currently above average in a European comparison, it is still much lower than the fertility levels that were recorded in the mid- $20^{\text {th }}$ century baby boom. It should also be noted that fertility levels in Belarusian urban areas remain quite low, even though they are in certain aspects higher than during the Soviet era. Given that urbanization is continuing in Belarus, the long-term sustainability of the recent increases may be in doubt. Nevertheless, the recent fertility improvements are very helpful for Eastern European societies, providing them with opportunities to alleviate the challenges associated with the drastic aging processes that they currently face.

Whether retraditionalization offers societies with lowest-low fertility a pathway to higher fertility might depend on the level of gender equality that has been achieved (i.e., at which point in the imagined U-shaped relationship a society is situated) (Esping-Andersen and Billari 2013). In Eastern Europe, the lower general level of gender equality may offer societies the opportunity to reach higher fertility levels through retraditionalization. This option might not be available for societies with higher gender equality levels, where a return to lower gender equality levels would instead lead to lower fertility levels. But also for Eastern Europe only time will tell whether observable tendencies towards retraditionalization can be sustained over longer periods of time. If not, the Eastern European "baby boom" might come to an end as quickly as its mid-20 $0^{\text {th }}$-century counterpart.

\section{References}

Alam, Asad, Mamta Murthi, Ruslan Yemtsov, Edmundo Murrugarra, Nora Dudwick, Ellen Hamilton, and Erwin Tiongson. 2005. Growth, Poverty and Inequality: Eastern Europe and the Former Soviet Union. Washington, DC: World Bank.

Andersson, Gunnar, and Dimiter Philipov. 2002. "Life-table representations of family dynamics in Sweden, Hungary, and 14 other FFS countries: A project of descriptions of demographic behavior." Demographic Research 7(Art. 4): 67-270.

Aslund, Anders. 2013. How Capitalism Was Built: The Transformation of Central and Eastern Europe, Russia, the Caucasus, and Central Asia. New York: Cambridge University Press.

Baxter, Janeen, Sandra Buchler, Francisco Perales, and Mark Western. 2014. "A lifechanging event: First births and men's and women's attitudes to mothering and gender divisions of labor." Social Forces 93(3), 989-1014.

Beets, Gijs C. N., Aart C. Liefbroer, and Jenny Gierveld. 1999. "Changes in fertility values and behaviour: A life course perspective." In Dynamics of Values in Fertility Change, edited by Richard Leete, 100-120. Oxford: Oxford University Press.

Bell, Martin, and Salut Muhidin. 2009. "Cross-National Comparisons of Internal Migration (No. HDRP-2009-30).” Human Development Research Paper Series 2009/30. New 
York: Human Development Report Office (HDRO), United Nations Development Programme (UNDP).

Belstat [National Statistical Committee of the Republic of Belarus]. 2017. Demographic Yearbook of the Republic of Belarus. Minsk: Belstat.

Bongaarts, John, and Tomáš Sobotka. 2012. "A demographic explanation for the recent rise in European fertility." Population and Development Review 38(1): 83-120.

Brandtstädter, Jochen, and Klaus Rothermund. 2002. "The life-course dynamics of goal pursuit and goal adjustment: A two-process framework." Developmental Review 22(1): $117-150$.

Brewster, Karin L., and Ronald R. Rindfuss. 2000. "Fertility and women's employment in industrialized nations.” Annual Review of Sociology 26(1): 271-296.

Caldwell, John C. 2001. "The globalization of fertility behavior." Population and Development Review 27(Supplement): 93-115.

Cockerham, William C. 2012. "The intersection of life expectancy and gender in a transitional state: the case of Russia." Sociology of Health \& Illness 34(6): 943-957.

Drummond, Paulo, Vimal Thakoor, and Shu Yu. 2014. Africa rising: Harnessing the Demographic Dividend (No. 14-143). Washington: International Monetary Fund.

Engelhardt, Henriette, and Alexia Prskawetz. 2004. "On the changing correlation between fertility and female employment over space and time." European Journal of Population/Revue européenne de Démographie 20(1): 35-62.

Eremenko, Marina M. 2016. "Stanovleniye gosudarstvennoy zhilishchnoy politiki Respubliki Belarus v period posle raspada SSSR do ekonomicheskogo krizisa 2011 g." Izvestiya Gomelskogo gosudarstvennogo universiteta imeni F. Skoriny 5(98): 112-117.

Esping-Andersen, Gøsta, and Francesco C. Billari. 2015. "Re-theorizing family demographics." Population and Development Review 41(1): 1-31.

Fisher, Robert J. 1993. "Social desirability bias and the validity of indirect questioning." Journal of Consumer Research 20(2): 303-315.

Fodor, Éva, and Anikó Balogh. 2010. "Back to the kitchen? Gender role attitudes in 13 East European countries." Zeitschrift für Familienforschung 22(3): 289-307.

Fox, Jonathan, Sebastian Klüsener, and Mikko Myrskylä. 2018. "Is a positive relationship between fertility and economic development emerging at the sub-national regional level? Theoretical considerations and evidence from Europe." European Journal of Population (Online First): 1-32.

Frejka, Tomas, and Stuart Gietel-Basten [and contributing authors]. 2016. "Fertility and family policies in Central and Eastern Europe after 1990." Comparative Population Studies 41(1): 3-56.

Frejka, Tomas, and Sergei Zakharov. 2013. "The apparent failure of Russia's pronatalist family policies." Population and Development Review 39(4): 635-647. 
Goldscheider, Frances, Eva Bernhardt, and Trude Lappegård. 2015. "The gender revolution: A framework for understanding changing family and demographic behavior." Population and Development Review 41(2): 207-239.

Goldstein, Joshua R., and Sebastian Klüsener. 2014. "Spatial analysis of the causes of fertility decline in Prussia." Population and Development Review 40(3): 497-525.

Goldstein, Joshua R., Tomáš Sobotka, and Aiva Jasilioniene. 2009. "The end of "lowest-low" fertility?" Population and Development Review 35(4): 663-699.

Höfner, Claudia, Cornelia Schadler, and Rudolf Richter. 2011. "When men become fathers: men's identity at the transition to parenthood.” Journal of Comparative Family Studies 42(5): 669-686.

Hudde, Ansgar. 2018. "Societal agreement on gender role attitudes and childlessness in 38 countries." European Journal of Population [Online First]: 1-23.

Huinink, Johannes, and Martin Kohli. 2014. "A life-course approach to fertility." Demographic Research 30(Art. 45); 1293-1326.

Human Fertility Database. Max Planck Institute for Demographic Research (Germany) and Vienna Institute of Demography (Austria). Available at www.humanfertility.org (data downloaded on 26/09/2018).

Imbrogno, Salvatore. 1986. "Family Policy in the Soviet Union." International Journal of Sociology of the Family 16(2): 165-180.

IPC [International Population Conference]. 2009. "Will the Second Demographic Transition be global?" session at the IPC. Marrakech. 27 September-2 October.

Kirk, Dudley. 1996. "Demographic transition theory." Population Studies 50(3): 361-387.

Klüsener, Sebastian. 2015. "Spatial variation in non-marital fertility across Europe in the twentieth and twenty-first centuries: recent trends, persistence of the past, and potential future pathways." The History of the Family 20(4): 593-628.

Kuzio, Taras. 2001. "Transition in post-communist states: Triple or quadruple?" Politics 21(3): 168-177.

Lappegård, Trude, Sebastian Klüsener, and Daniele Vignoli. 2018. "Why are marriage and family formation increasingly disconnected across Europe? A multilevel perspective on existing theories." Population, Space and Place 24(2): e2088.

Lesthaeghe, Ron. 2010. "The unfolding story of the second demographic transition." Population and Development Review 36(2): 211-251.

Lima, Everton D., Zeman, Kryštof, Tomaš Sobotka, Mathias Nathan, and Ruben Castro. 2018. "The emergence of bimodal fertility profiles in Latin America." Population and Development Review (Early View).

Lois, Dabiek, and Oliver Arránz Becker. 2014. "Is fertility contagious? Using panel data to disentangle mechanisms of social network influences on fertility decisions." Advances in Life Course Research 21: 123-134. 
Macours, Karen, and Johan F. Swinnen. 2008. "Rural-urban poverty differences in transition countries." World Development 36(11): 2170-2187.

Mishra, Ankita, and Jaai Parasnis. 2017. "Peers and fertility preferences: An empirical investigation of the role of neighbours, religion and education." Social Indicators Research 134(1): 339-357.

Müller, Marion, and Nicole Zillien 2016. Das Rätsel der Retraditionalisierung-Zur Verweiblichung von Elternschaft in Geburtsvorbereitungskursen. KZfSS Kölner Zeitschrift für Soziologie und Sozialpsychologie 68(3): 409-433.

Myrskylä, Mikko, Joshua R. Goldstein, and Yen-shin A. Cheng. 2013. "New cohort fertility forecasts for the developed world: Rises, falls, and reversals." Population and Development Review 39(1): 31-56.

Nederhof, Anton J. 1985. "Methods of coping with social desirability bias: A review." European Journal of Social Psychology 15(3): 263-280.

Neyer, Gerda, and Gunnar Andersson. 2008. "Consequences of family policies on childbearing behavior: Effects or artifacts?" Population and Development Review 34(4): 699724.

Perelli-Harris, Brienna, and Ted P. Gerber. 2011. "Nonmarital childbearing in Russia: Second demographic transition or pattern of disadvantage?" Demography 48(1): 317-342.

Philipov, Dimiter, and Aiva Jasilioniene. 2008. "Union formation and fertility in Bulgaria and Russia: A life table description of recent trends." Demographic Research 19(Art. 62): 2057-2114.

Shakhotko, Lyudmila P. 2009. Model demograficheskogo razvitiya Respubliki Belarus. Minsk: Belaruskaya navuka.

Shakhotko, Lyudmila P., and Dmitri V. Shakhotko. 2018. Domokhozyaystvo, semya i semeynaya politika v Belarusi. Minsk: Belaruskaya navuka.

Sobotka, Tomáš. 2003. "Re-emerging diversity: Rapid fertility changes in Central and Eastern Europe after the collapse of the communist regimes." Population (English Edition) 58(4/5): 451-485.

Szołtysek, Mikołaj, Sebastian Klüsener, Radosław Poniat, and Siegfried Gruber. 2017. "The Patriarchy Index: A new measure of gender and generational inequalities in the past." Cross-Cultural Research 51(3): 228-262.

Thornton, Arland, and Dimiter Philipov. 2009. "Sweeping changes in marriage, cohabitation and childbearing in Central and Eastern Europe: New insights from the developmental idealism framework." European Journal of Population/Revue européenne de Démographie, 25(2): 123-156.

Thornton, Arland. 2013. Reading History Sideways: The Fallacy and Enduring Impact of the Developmental Paradigm on Family Life. Chicago: University of Chicago Press.

United Nations. 2016. World Population Policies Database: 2015 Revision. New York: United Nations. 
Van Bavel, Jan. 2010. "Subreplacement fertility in the West before the baby boom: Past and current perspectives." Population Studies 64(1): 1-18.

Van Bavel, Jan, and David S. Reher. 2013. "The Baby Boom and its causes: What we know and what we need to know." Population and Development Review 39(2): 257-288.

Yuodeshko, Viktoriya I. 2017. “Tendentsii rozhdayemosti v Respublike Belarus.” In Sostoyaniye $i$ perspektivy demograficheskogo razvitiya Respubliki Belarus, edited by T.N. Mironovoy and S.V. Ryazantseva, 23-38. Minsk: V.I.Z.A. Grupp.

Yuodeshko, Viktoriya I. 2012. "Mery ekonomicheskoy podderzhki semey s detmi i ikh vliyaniye na rozhdayemost: retrospektivnyy analiz." Problemy upravleniya 3: 94-99.

Zakharov, Sergei. 2008. "Russian Federation: From the first to second demographic transition." Demographic Research - Special Collection 7: Childbearing Trends and Policies in Europe 19(24): 907-972. 
Fig. 1: Fertility trends in Eastern Europe and other selected countries

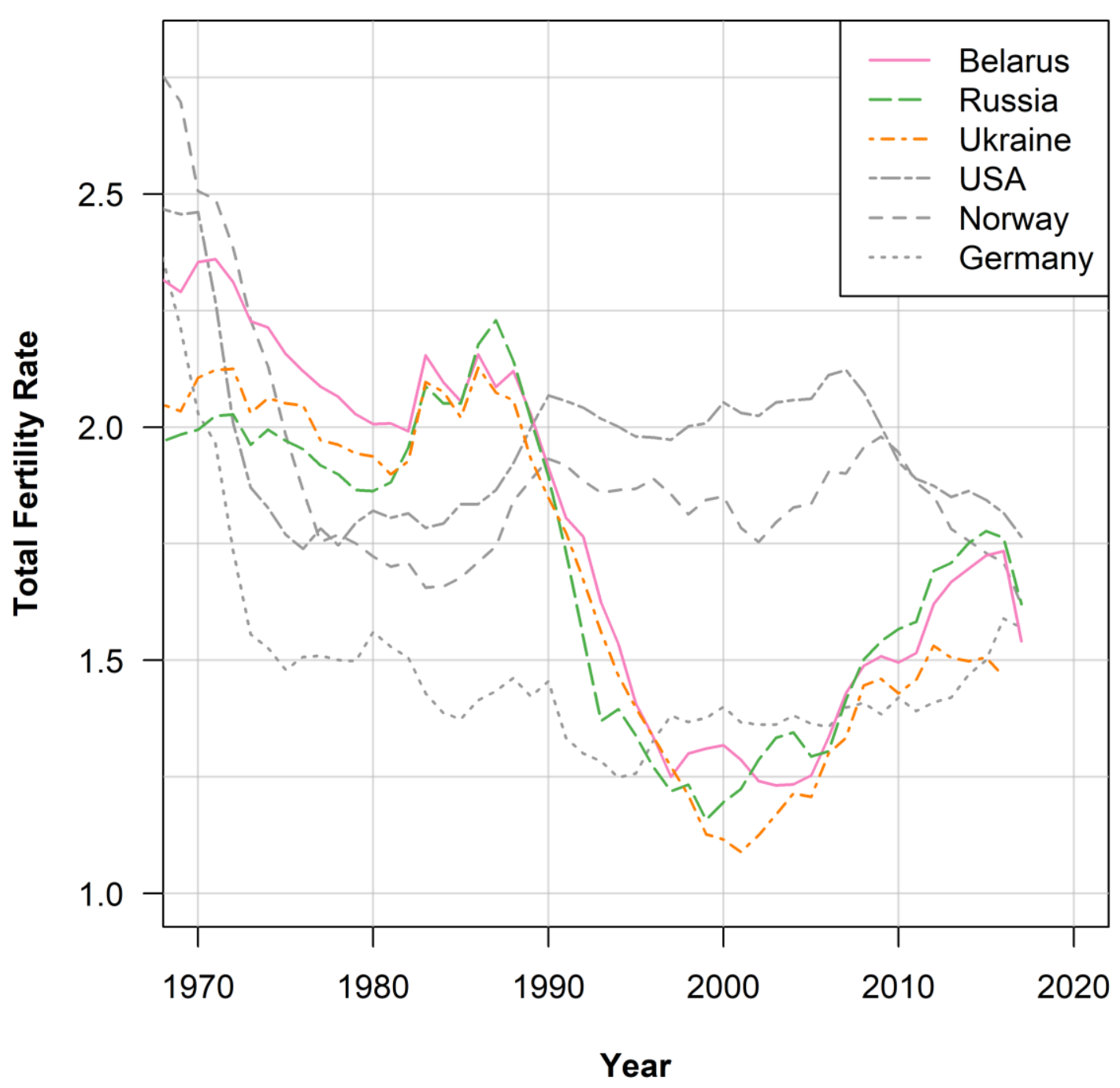

Note: Data for Ukraine from 2014 on without Crimea and Sevastopol and occupied territories in eastern Ukraine. Data for Russia include from 2015 on statistics for Crimea including Sevastopol.

Source: Human Fertility Database, Data for most recent years from national sources (in part preliminary) 
Fig. 2: Cumulative percentage increases by birth order (period/synthetic cohort perspective)

First Birth - Period (Belarus)

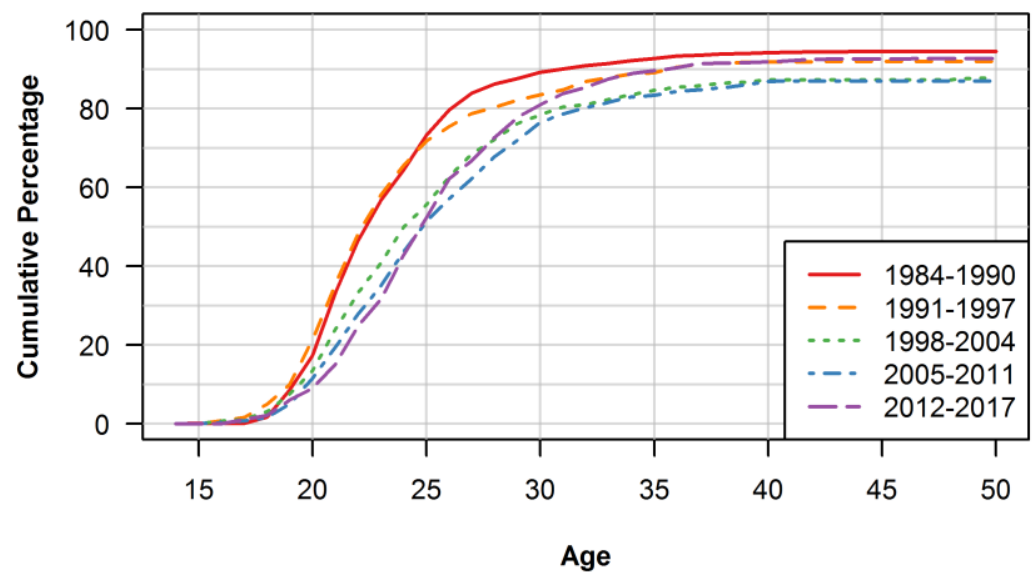

Second Birth - Period (Belarus)

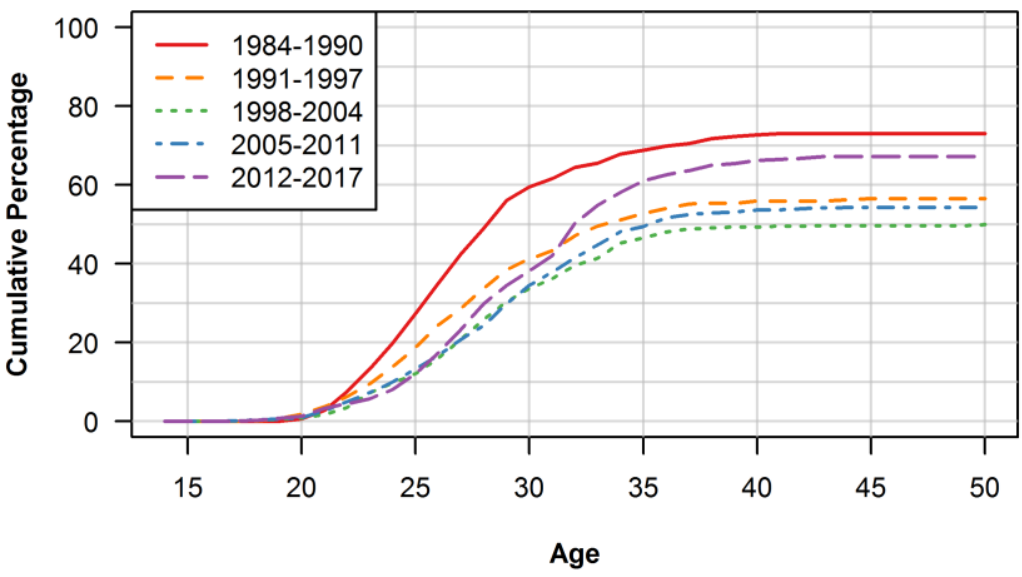

Third Birth - Period (Belarus)

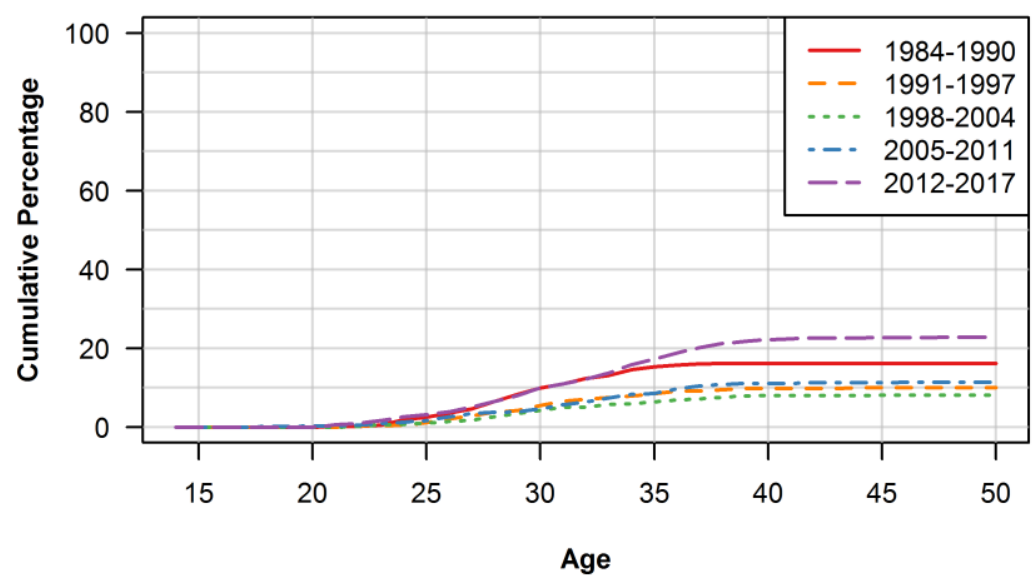

Source: Belarusian GGS, own calculations 
Fig. 3: Cumulative percentage increases by birth order (cohort perspective)

First Birth - Cohort (Belarus)

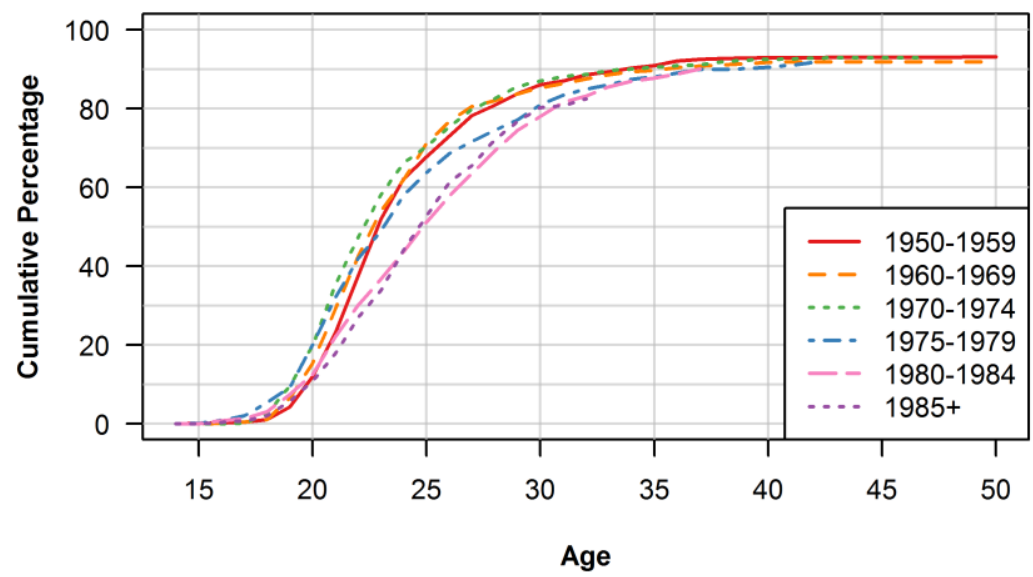

Second Birth - Cohort (Belarus)

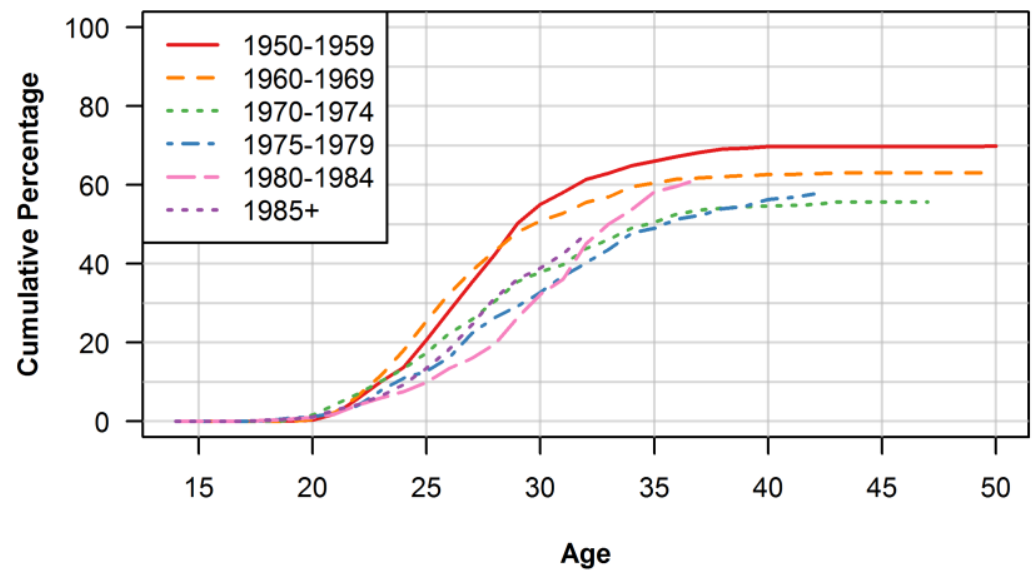

Third Birth - Cohort (Belarus)

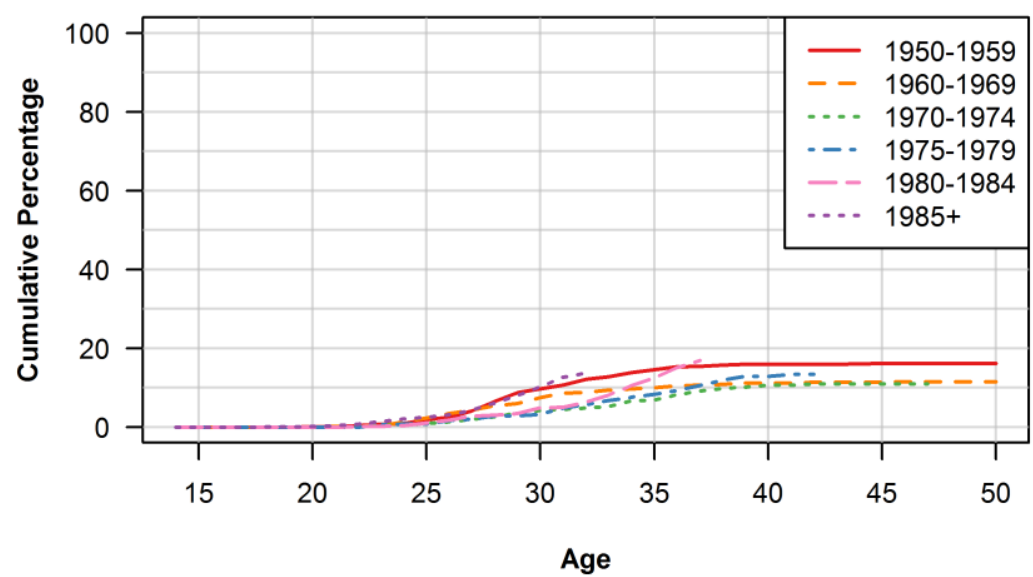

Source: Belarusian GGS, own calculations 
Fig. 4: Cumulative percentage increases by birth order and urban/rural place of residence (period/synthetic-cohort perspective)

First Birth - Period (Belarus - Urban)

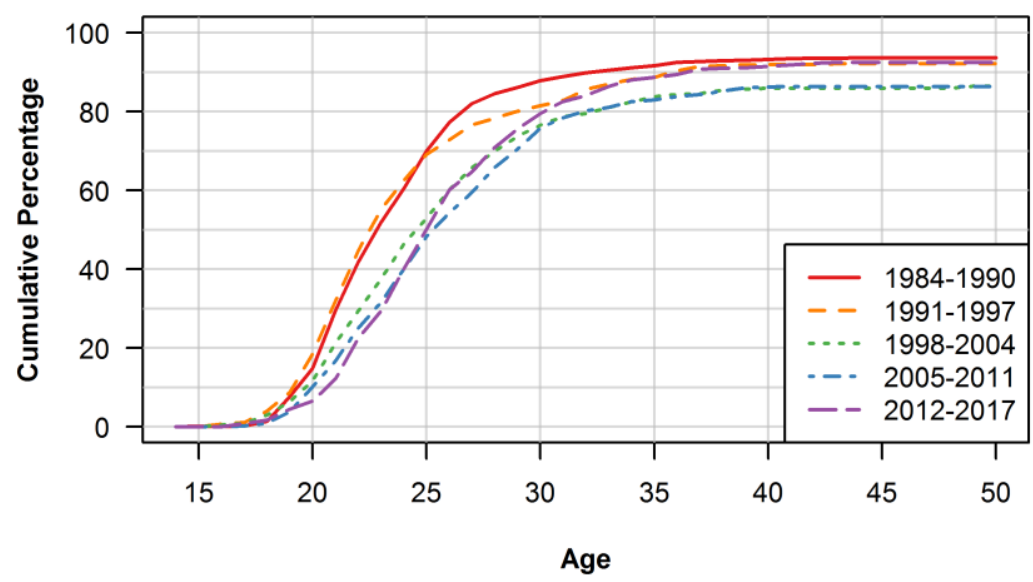

Second Birth - Period (Belarus - Urban)

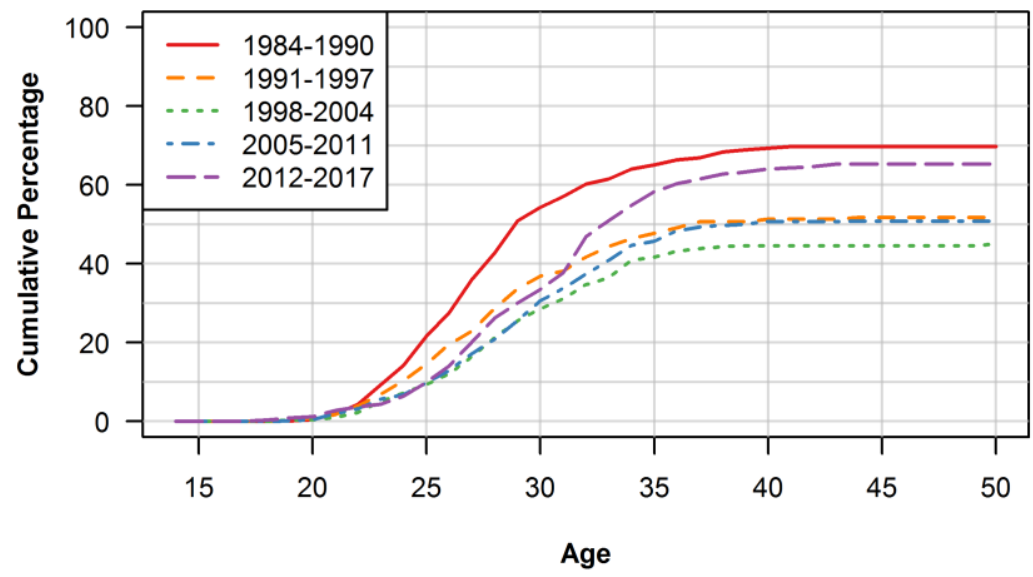

Third Birth - Period (Belarus - Urban)

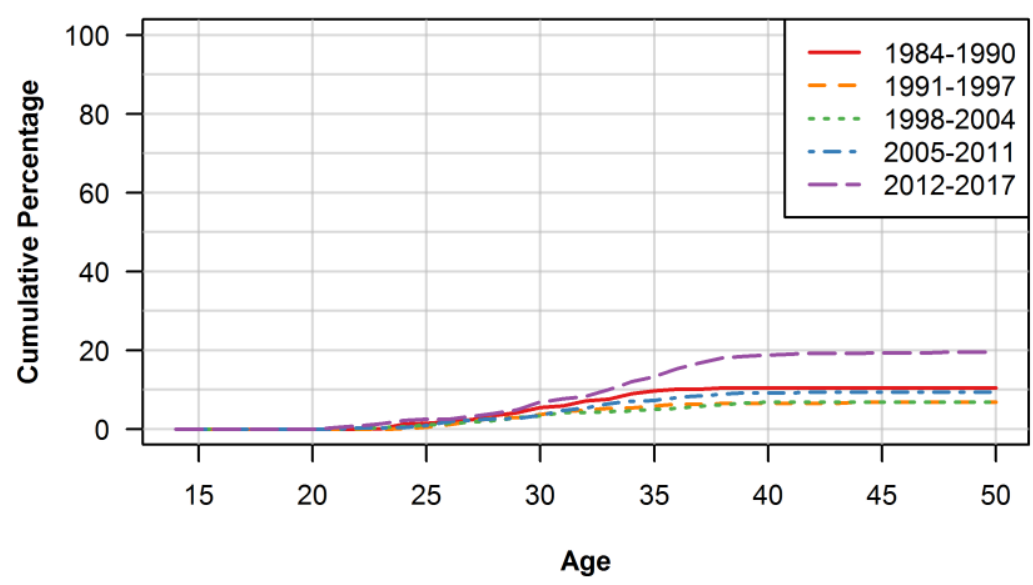


First Birth - Period (Belarus - Rural)

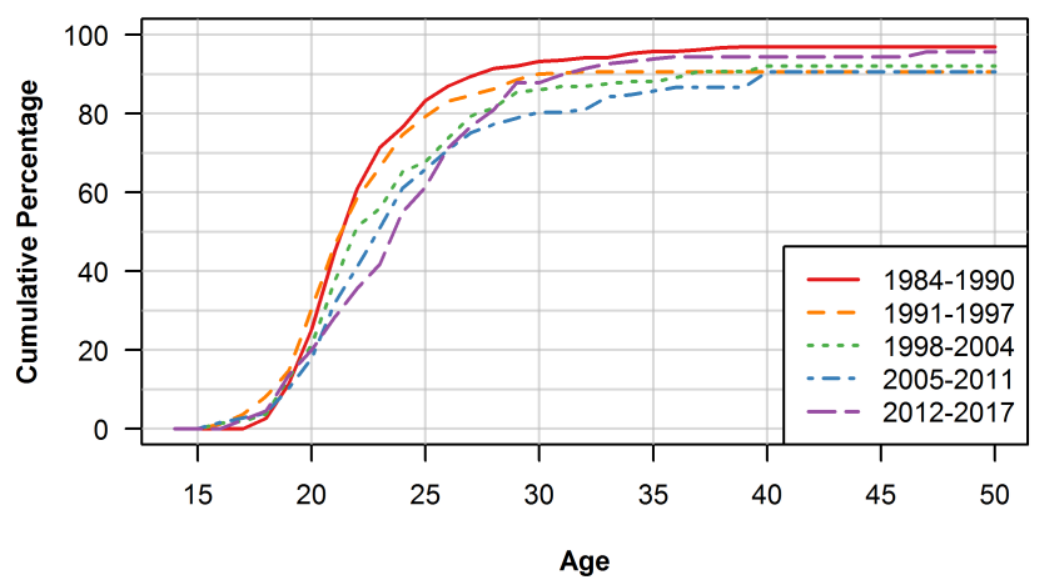

Second Birth - Period (Belarus - Rural)

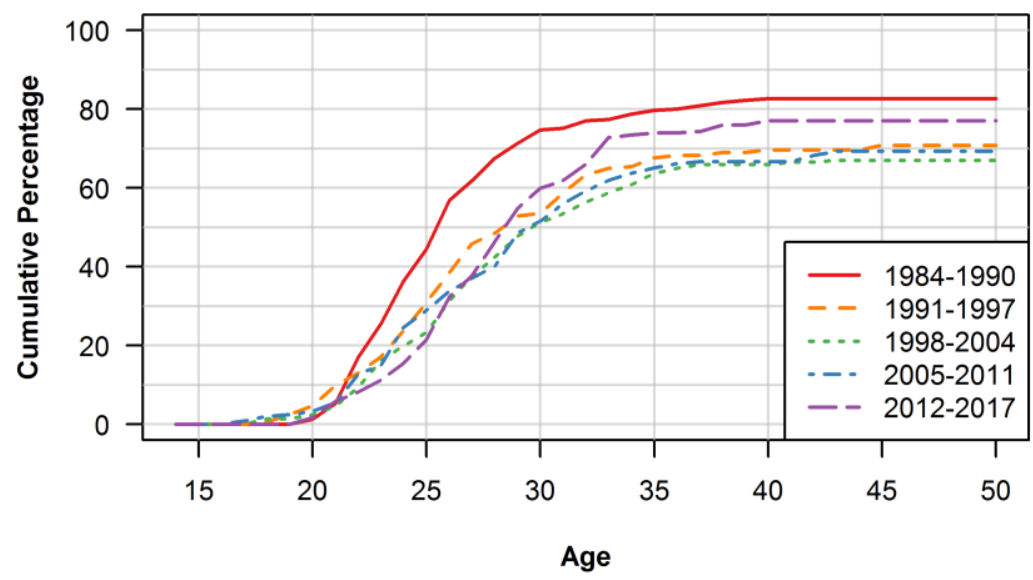

Third Birth - Period (Belarus - Rural)

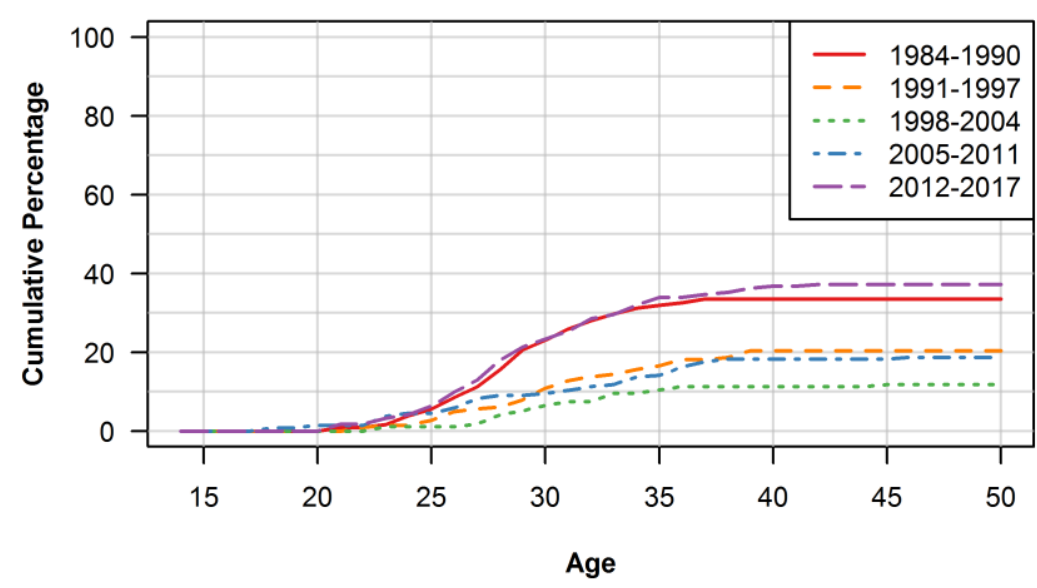

Source: Belarusian GGS, own calculations 
Fig. 5: Cumulative percentage increases by birth order and urban/rural place of residence (cohort perspective)

First Birth - Cohort (Belarus - Urban)

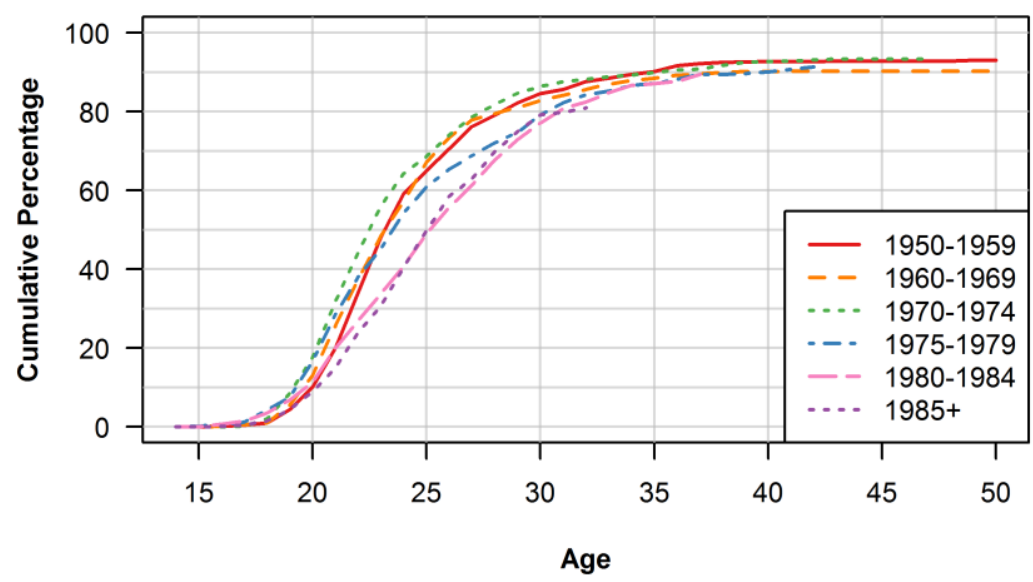

Second Birth - Cohort (Belarus - Urban)

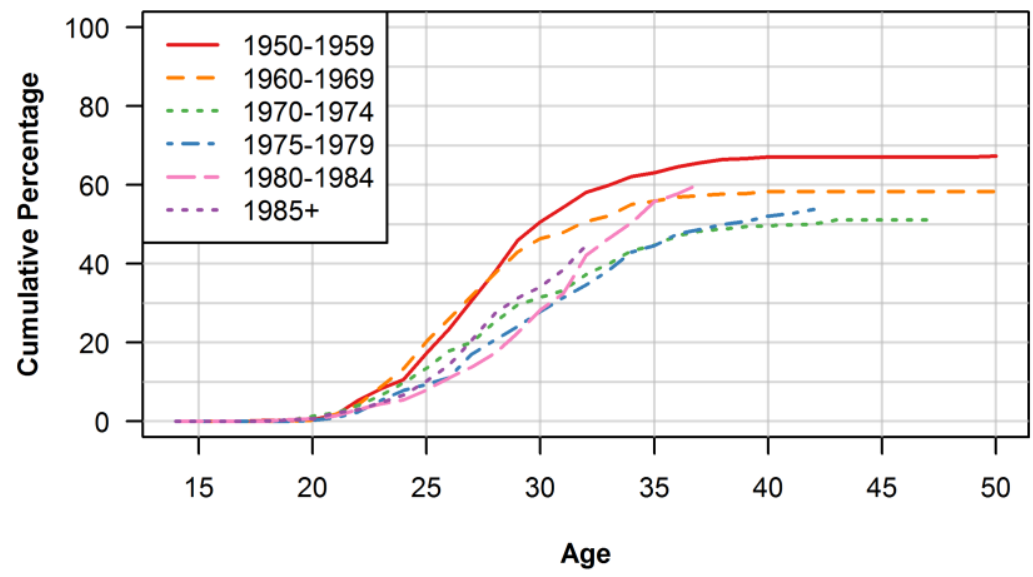

Third Birth - Cohort (Belarus - Urban)

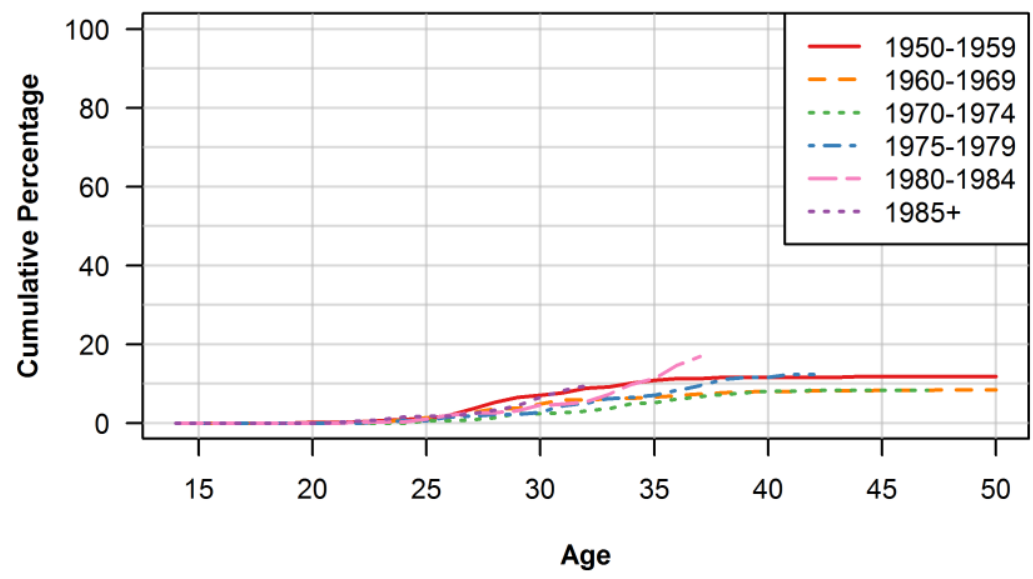


First Birth - Cohort (Belarus - Rural)

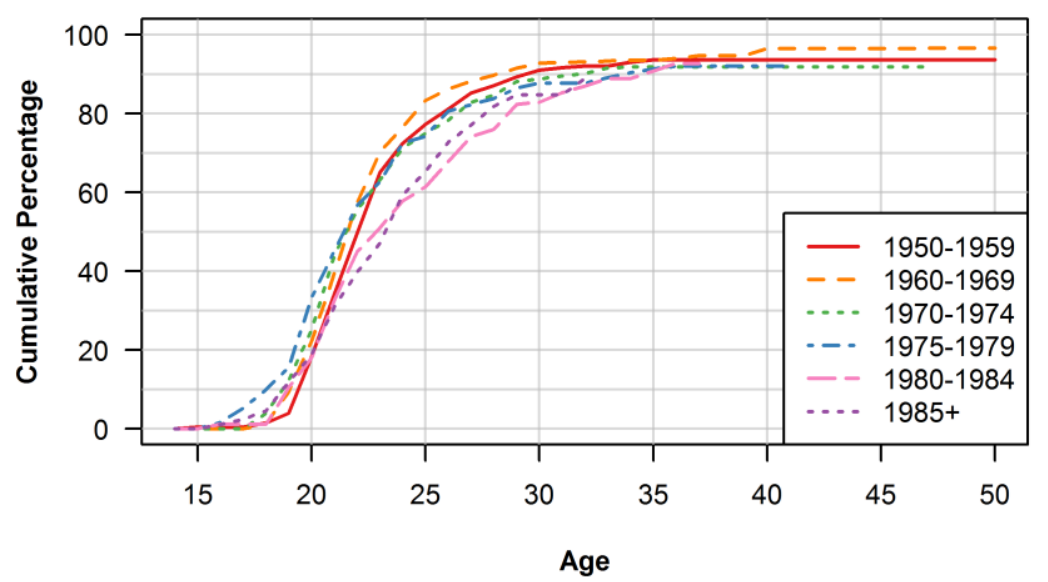

Second Birth - Cohort (Belarus - Rural)

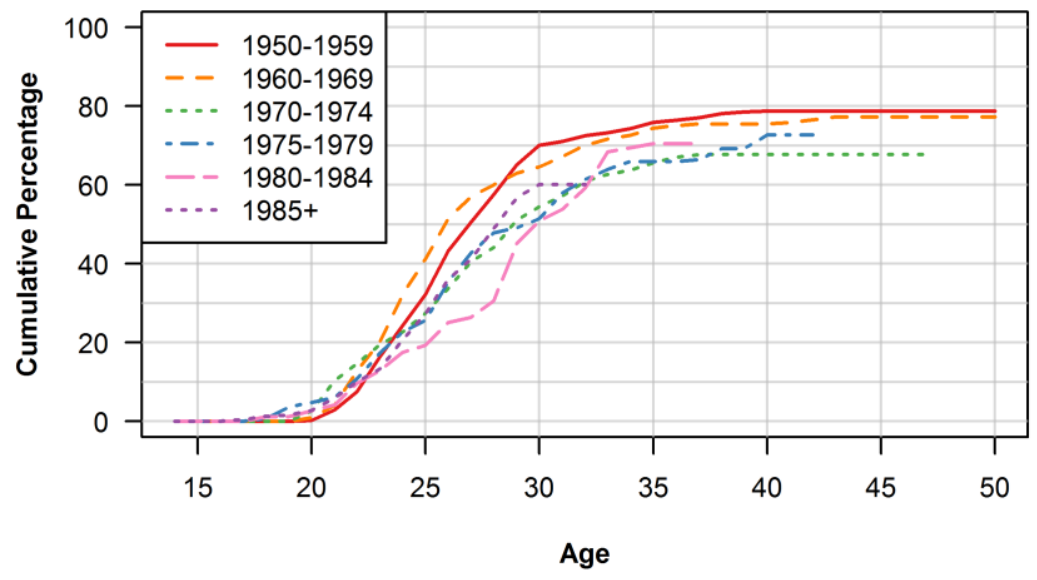

Third Birth - Cohort (Belarus - Rural)

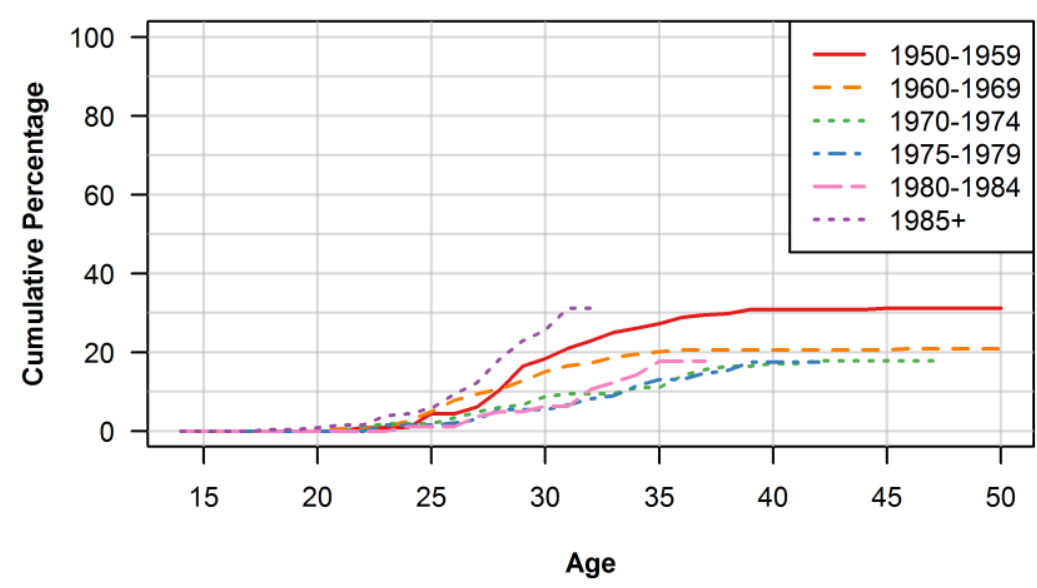

Source: Belarusian GGS, own calculations 
Fig. 6: Smoothed hazards rates for having a second and a third birth (period/synthetic cohort perspective)
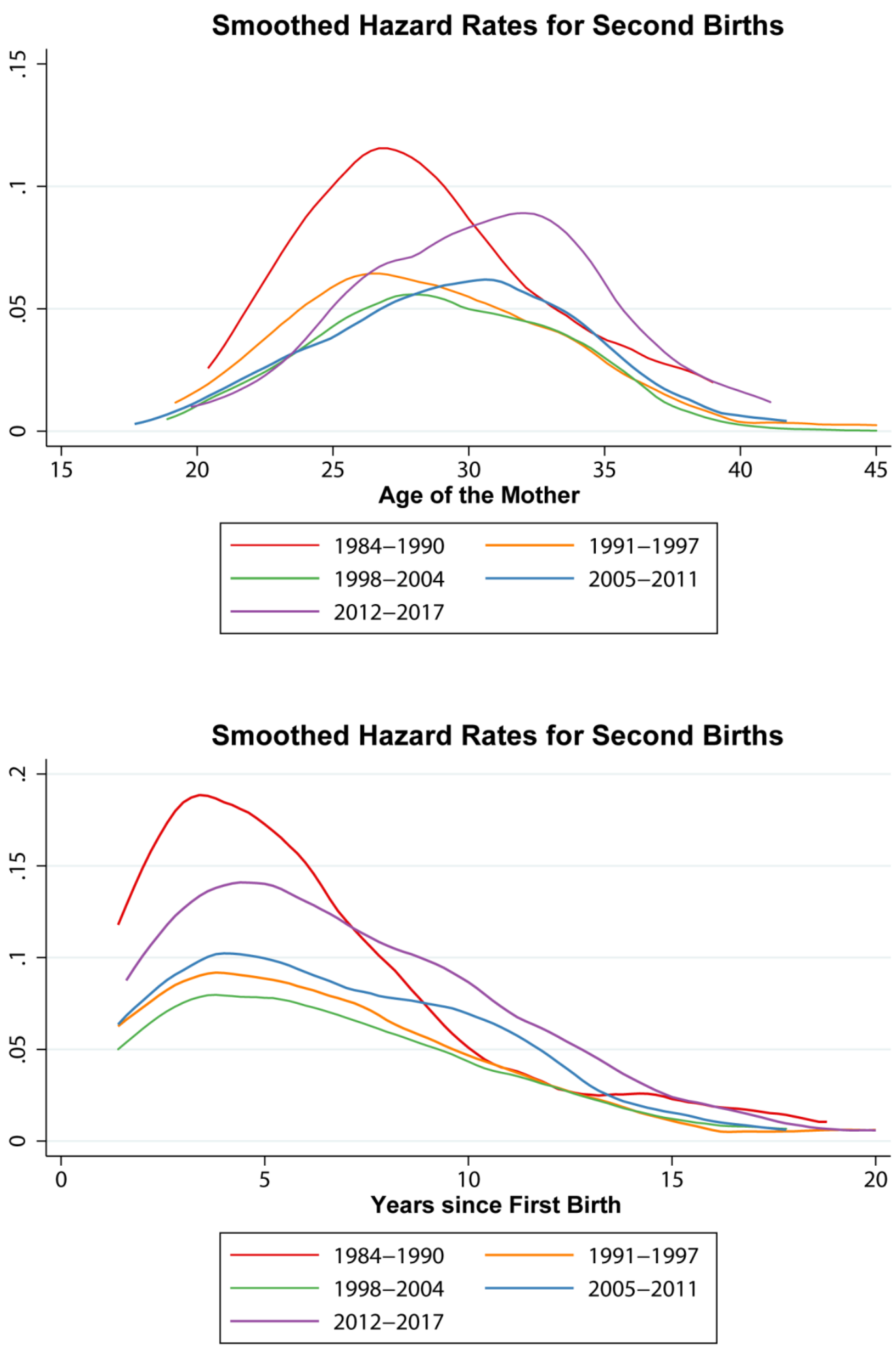

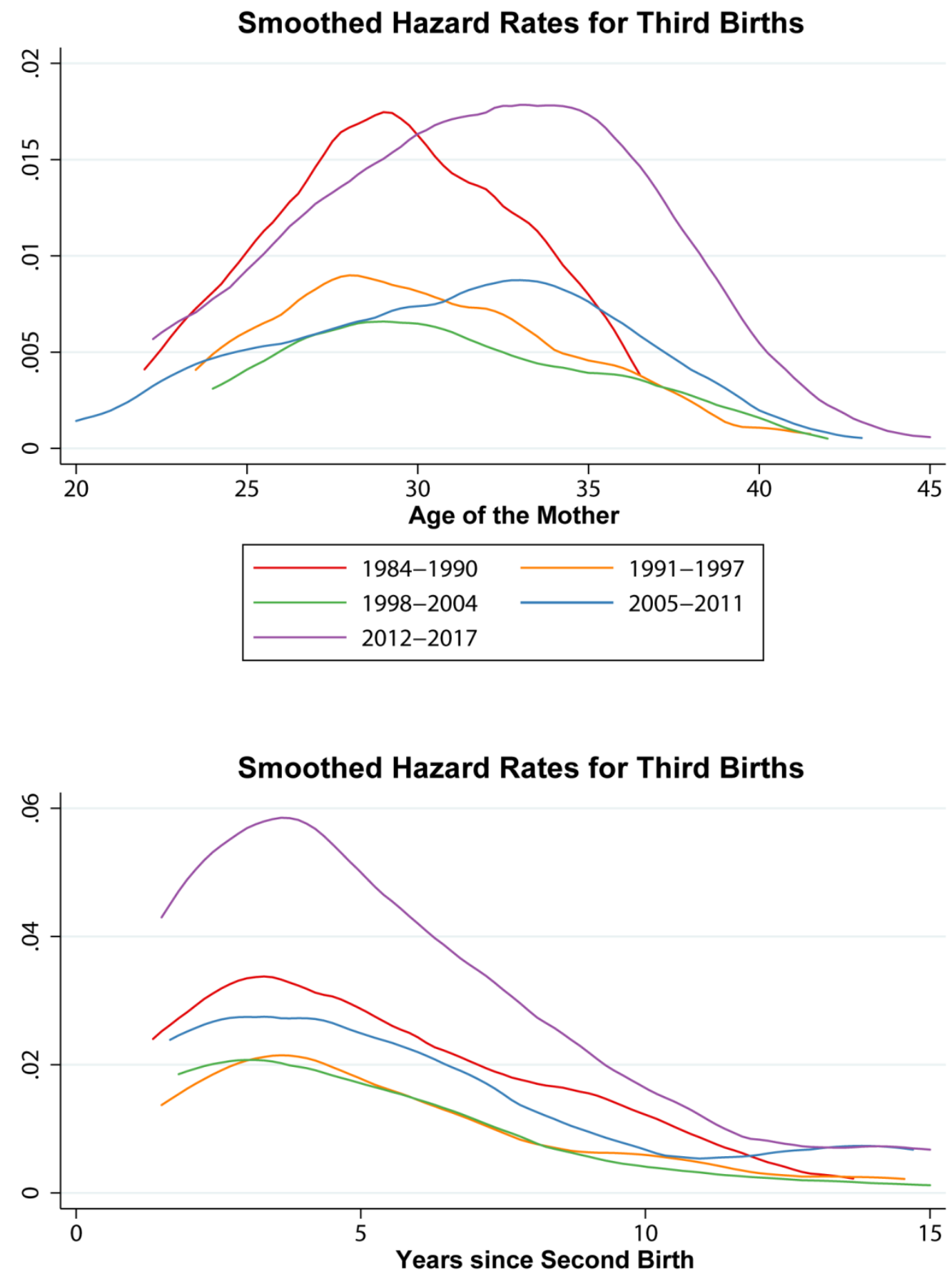

\begin{tabular}{|rr|r|}
\hline $1984-1990$ & $1991-1997$ \\
\hline & $1998-2004$ & 2005-2011 \\
$2012-2017$ & \\
\hline
\end{tabular}

Source: Belarusian GGS, own calculations 
Table 1: Cohort trends in gender attitudes about who should earn money for the family (Share who agree definitely or slightly that the man is mainly responsible)

\begin{tabular}{lllllll}
\hline & Belarus & Urban & Rural & Female \\
\hline $1940-49$ & $70.1 \%(298)$ & $49.6 \%(593)$ & $67.7 \%(226)$ & $49.0 \%(443)$ & $77.8 \%(72)$ & $51.3 \%(150)$ \\
$1950-59$ & $63.5 \%(669)$ & $55.2 \%(1010)$ & $62.4 \%(484)$ & $54.7 \%(775)$ & $66.5 \%(185)$ & $56.6 \%(235)$ \\
$1960-69$ & $62.6 \%(716)$ & $51.1 \%(940)$ & $61.1 \%(512)$ & $50.7 \%(697)$ & $66.2 \%(204)$ & $52.3 \%(243)$ \\
$1970-74$ & $62.5 \%(387)$ & $51.0 \%(500)$ & $61.2 \%(296)$ & $51.9 \%(370)$ & $67.0 \%(91)$ & $48.5 \%(130)$ \\
$1975-79$ & $64.5 \%(425)$ & $51.0 \%(537)$ & $64.7 \%(334)$ & $51.8 \%(429)$ & $63.7 \%(91)$ & $48.2 \%(108)$ \\
$1980-84$ & $65.4 \%(486)$ & $58.6 \%(517)$ & $67.3 \%(398)$ & $58.3 \%(432)$ & $56.8 \%(88)$ & $60.0 \%(85)$ \\
$1985-89$ & $69.5 \%(547)$ & $60.7 \%(494)$ & $69.7 \%(466)$ & $61.2 \%(397)$ & $67.9 \%(81)$ & $58.8 \%(97)$ \\
$1990-94$ & $66.9 \%(484)$ & $61.6 \%(411)$ & $66.7 \%(417)$ & $63.2 \%(326)$ & $68.7 \%(67)$ & $55.3 \%(85)$ \\
$1995-99$ & $60.8 \%(380)$ & $54.7 \%(320)$ & $60.9 \%(317)$ & $54.2 \%(262)$ & $60.3 \%(63)$ & $56.9 \%(58)$ \\
\hline
\end{tabular}

Notes: Total number of valid answers per cohort group are provided in brackets.

Source: Belarusian GGS, own calculations

Table 2: Cohort trends in gender attitudes about who should take care of children (Share who agree definitely or slightly that the woman is mainly responsible)

\begin{tabular}{lllllll}
\hline & Belarus & Urban & Rural & \\
& Male & Female & Male & Female & Male & Female \\
\hline $1940-49$ & $45.3 \%(298)$ & $39.7 \%(594)$ & $45.1 \%(226)$ & $39.1 \%(443)$ & $45.8 \%(72)$ & $41.7 \%(151)$ \\
$1950-59$ & $40.0 \%(670)$ & $35.9 \%(1012)$ & $38.7 \%(486)$ & $36.0 \%(777)$ & $43.5 \%(184)$ & $35.3 \%(235)$ \\
$1960-69$ & $35.2 \%(715)$ & $33.6 \%(939)$ & $37.2 \%(511)$ & $33.8 \%(696)$ & $30.4 \%(204)$ & $32.9 \%(243)$ \\
$1970-74$ & $35.5 \%(386)$ & $36.4 \%(500)$ & $36.8 \%(296)$ & $36.8 \%(370)$ & $31.1 \%(90)$ & $35.4 \%(130)$ \\
$1975-79$ & $38.4 \%(427)$ & $38.5 \%(538)$ & $40.5 \%(336)$ & $39.3 \%(430)$ & $30.8 \%(91)$ & $35.2 \%(108)$ \\
$1980-84$ & $40.0 \%(485)$ & $37.2 \%(516)$ & $40.8 \%(397)$ & $37.0 \%(432)$ & $36.4 \%(88)$ & $38.1 \%(84)$ \\
$1985-90$ & $37.6 \%(545)$ & $39.0 \%(495)$ & $37.1 \%(464)$ & $37.8 \%(399)$ & $40.7 \%(81)$ & $43.8 \%(96)$ \\
$1990-94$ & $35.7 \%(484)$ & $44.0 \%(414)$ & $36.5 \%(417)$ & $44.4 \%(329)$ & $31.3 \%(67)$ & $42.4 \%(85)$ \\
$1995-99$ & $44.2 \%(380)$ & $48.0 \%(321)$ & $43.5 \%(317)$ & $47.9 \%(263)$ & $47.6 \%(63)$ & $48.3 \%(58)$ \\
\hline
\end{tabular}

Notes: Total number of valid answers per cohort group are provided in brackets.

Source: Belarusian GGS, own calculations 


\section{Appendix: Consistency checks between GGS data and official birth registration data}

To investigate the representativeness of the GGS data, we compared trends in the mean age for the first, second, and third birth as derived from the survey data with data from the $\mathrm{Hu}$ man Fertility Database (HFD). We focus on the period since the mid-1980s (see Fig. A1). The mean ages at childbirth from the survey data are calculated based on intervals of seven years (e.g., for the period 1984-1990). For the mean age at first birth, the match is very good over most of the observation period, except during the years before the survey, for which the mean age derived from the GGS is slightly above the values obtained from the HFD. However, the upward trend in the mean age at first childbirth visible in the HFD data is also mirrored by the GGS data. For second births, the fit is not as good as it is for first births, but it is still quite good, as only the estimate for the late 2000s is a bit too low. Thus, in general, the overall time trends for first and second births are similarly well captured. For third births, the confidence intervals are much bigger, and the means derived from the survey data are off in some periods. This is the case for the late 1980s and the late 2000s, for which the mean obtained from the survey data is one year below the mean provided by the HFD. Overall, the analysis gives the impression that the GGS data capture the trends in first and second births quite well. But while the developments for third births reported in the data are not completely off, the outcomes for third births should be interpreted with more caution. 
Figure A1: Trends in the mean age at childbirth ( $1^{\text {st }}$ to $3^{\text {rd }}$ birth)

Mean Age at First Birth (Belarus)

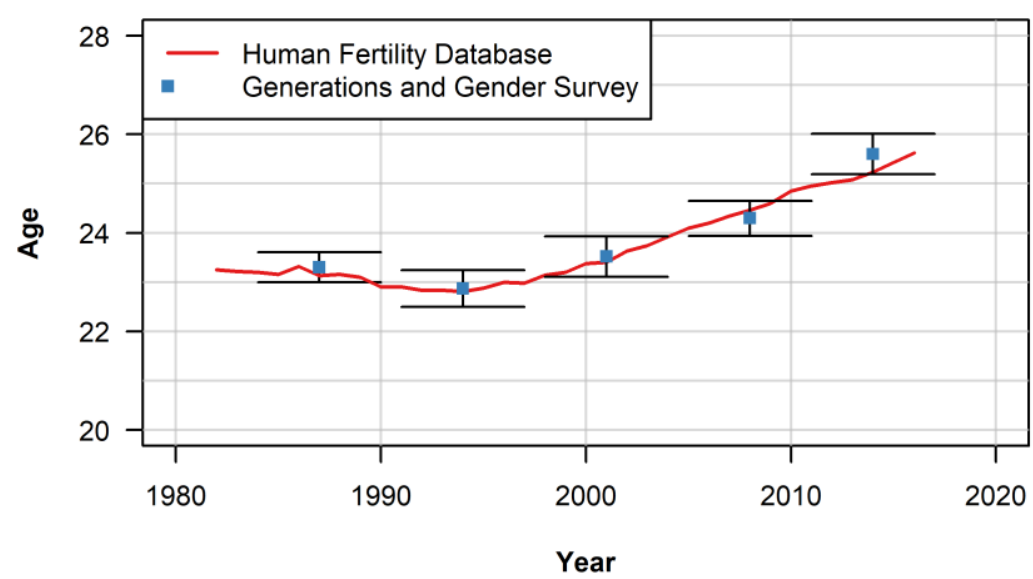

Mean Age at Second Birth (Belarus)

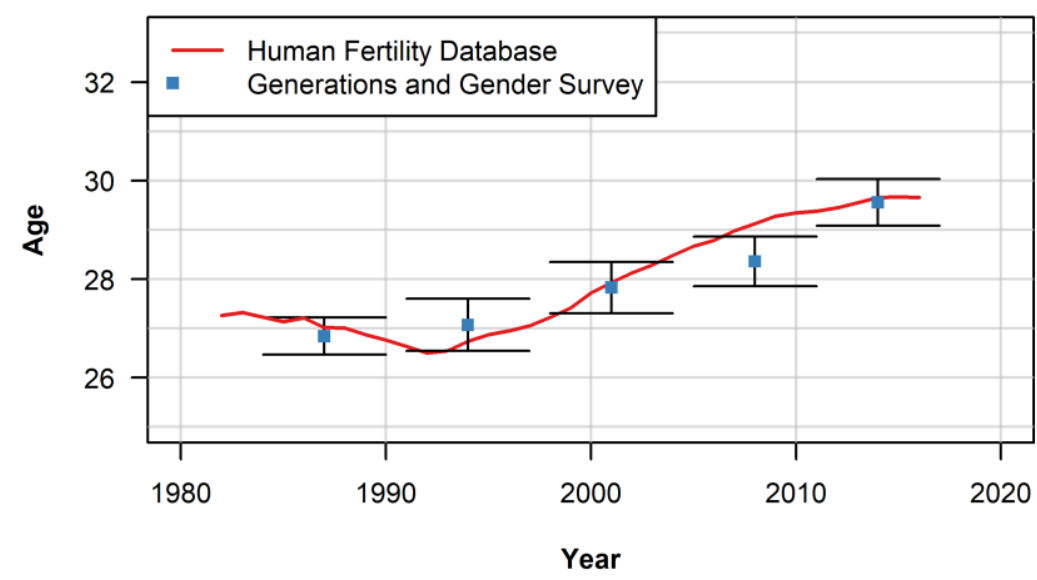

Mean Age at Third Birth (Belarus)

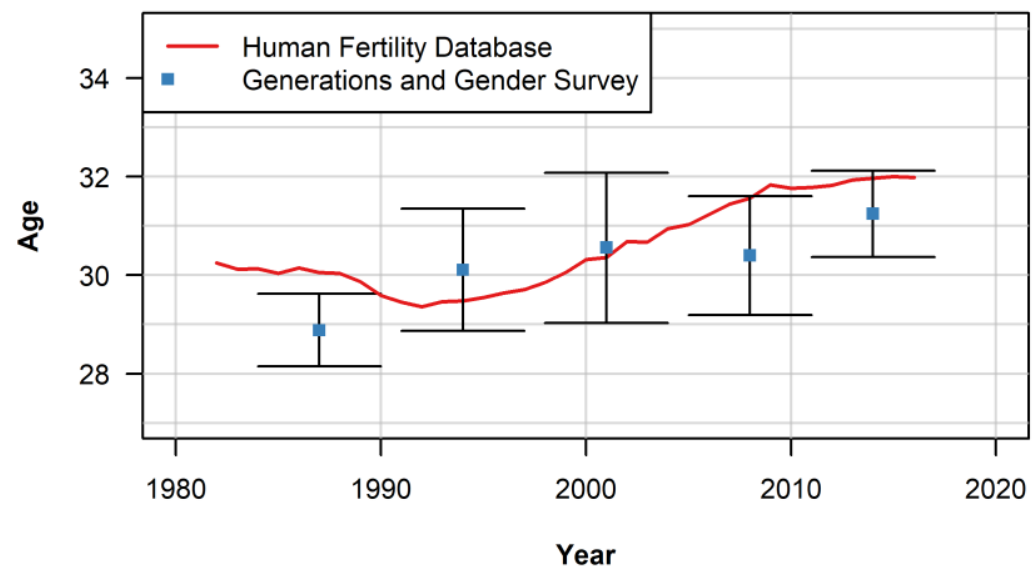

* Confidence intervals for the survey data are provided at the 95\%-level. In deriving the mean age at childbirth from the survey data, only births before age 45 are considered.

Source: Human Fertility Database, Belarusian GGS, own calculations 